\title{
A DESCOLONIZAÇÃO DO IMAGINÁRIO DOS DIREITOS HUMANOS
}

\author{
LA DECOLONIS ATION DE L'IMAGINAIRE DES DROITS DE L'HOMME
}

Gabriel Kafure da Rocha

\begin{abstract}
RESUMO: O presente artigo pretende fazer uma análise do imaginário social dos direitos humanos a partir da perspectiva da descolonização. Desse modo, em um primeiro momento investigaremos como reverberam os imaginários dos direitos humanos por meio do paradoxo entre cidadania e violência. Após esse levantamento, iremos analisar em perspectivas críticas da essência do papel das ONGs na construção e/ou descolonização desses direitos humanos no contexto cultural da realidade brasileira. Para isso, nos valeremos de teóricos como Paulina Chiziane, Achille Mbembe, Latouche e Castoriadis, estes dois últimos fundamentaram a própria descolonização do imaginário. Logo, a descolonização do imaginário, desenvolvida principalmente por Latouche visa tratar justamente de libertar o indivíduo das forças normalizadoras e homogeneizadoras, trazendoo de volta à singularidade de acreditar nos ideais que os direitos humanos propagam. Iremos contrapor essa perspectiva junto a ideia do fim do humanismo perante a tecnocracia pelo conceito de megamáquina de Latouche.
\end{abstract}

Palavras-chave: Megamáquina; cidadania; pós-humanismo.

RÉSUMÉ: Le présent document se propose d'analyser l'imaginaire social des droits de l'homme sous l'angle de la décolonisation. Ainsi, nous examinerons d'abord comment les imaginaires des droits de l'homme se répercutent dans le paradoxe entre citoyenneté et violence. Après cette enquête, nous analyserons dans des perspectives critiques l'essence du rôle des ONG dans la construction et / ou la décolonisation de ces droits de l'homme dans le contexte culturel de la réalité brésilienne. Pour ce faire, nous utiliserons des théoriciens tels que Paulina Chiziane, Achille Mbembe, Latouche et Castoriadis, ces deux derniers fondant la décolonisation même de l'imaginaire. Par conséquent, la décolonisation de l'imaginaire, développée principalement par Latouche, vise à libérer l'individu des forces normalisatrices et homogénéisantes, le ramenant à la singularité de croire aux idéaux que propagent les droits de l'homme. Nous allons contrer cette perspective avec l'idée de la fin de l'humanisme avant la technocratie par le concept de mégamachine de Latouche.

Mots-clés: Megamachine; citoyenneté; post-humanisme.

\section{Considerações Iniciais}

Mas essa espécie de revolução exigira mudanças profundas na estrutura psicossocial das pessoas no mundo ocidental, em sua atitude para com a vida, em suma, em seu imaginário. A ideia de que o único objetivo da vida é produzir e consumir mais é absurda e humilhante, e deve ser abandonada. O imaginário capitalista do pseudodomínio pseudorracional e da expansão ilimitada deve ser abandonado. somente homens e as mulheres podem fazer isso, Um único indivíduo ou uma organização só podem se 
preparar, criticar, incentivar e esboçar possíveis orientações, na melhor das hipóteses. (CASTORIADIS, 2010, p. 199)

Por considerar que toda filosofia é uma aproximação entre o que acreditamos e pensamos com a materialidade do que pretendemos atingir, pretendo iniciar a minha arguição partindo do meu prisma filosófico, minhas lentes pelas quais eu enxergo o mundo e adentro nos estudos do imaginário que serão as botas por onde caminha minha reflexão.

Dito isso, podemos partir da perspectiva de um imaginário político no Brasil onde o ressentimento e o desapontamento criam polaridades e desavenças, as quais, do ponto de vista conservador, buscam atacar principalmente os direitos humanos como uma perspectiva que visa preservar somente uma minoria, sejam ele criminosos ou mesmo pessoas como qualquer um de nós, que foram lesadas e são desde sempre injustiça das por não pertencer a uma classe privilegiada. Continuando um argumento que recentemente ouvi de um mecânico, o próprio criador dos direitos humanos se tivesse alguém de sua família agredido, violentado sexualmente, não defenderia o criminoso como os defensores dos direitos humanos costumam fazer.

Contrapondo essa visão por meio do resgate do princípio da equidade, aonde a igualdade é acompanhada por uma política afirmativa que iguala as oportunidades, do ponto de vista capitalista, muita gente concorda que uma empresa maior deve obter um maior incentivo do que uma empresa menor. Entretanto, esse discurso muda geralmente quando se trata não de corporações, mas sim de pessoas físicas, costumo ver pessoas favoráveis a meritocracia ao invés das cotas, por exemplo, e isso me parece no mínimo problemático levando em conta os valores econômicos acima dos valores humanos, éticos e morais.

Por essa problemática me volto a uma primeira questão na desconstrução ou descolonização dessa forma de pensamento a partir da própria genealogia dos direitos humanos. Apesar de ter sido elaborada principalmente por canadense, John Peters Humphrey, em 1948, a declaração universal dos direitos humanos contou com um amplo comitê com contribuições que visaram sintetizar o que há de mais igualitário em constituições pós-iluministas. Cabe lembrar que é após a Revolução francesa, que se inaugura o iluminismo, e é nessa revolução que nasceu o próprio conceito de direita e esquerda, quando os liberais girondinos e os extremistas jacobinos sentavam, respectivamente à direita e a esquerda no salão da assembleia nacional. 


\section{Um imaginário da declaração de direitos ao pós-humanismo}

Desde antes da revolução francesa até a criação dos direitos humanos, houve uma grande exploração imperialista das colônias europeias, então o primeiro conceito que viso abordar é justamente oposto à essa perspectiva: a descolonização. Descolonizar não é só o processo de tornar independe, portanto, autônomo, um país que foi outrora explorado econômica e culturalmente. Descolonizar é justamente tirar a subjetividade de um processo ou conceito aculturado para produzir espaços aos novos protagonistas sociais subalternizados pela colonização. Os colonizados em si, não eram nem direita nem esquerda, mas pelo menos no caso das colônias lusófonas, tomaram os valores socialistas como predicado para sua ideia de libertação. Assim, com exceção do Brasil, que foi antes tornado independente por um pacto oligárquico, Angola e Moçambique tiveram governos de tendência socialistas, que após tomarem o poder, pela não bilateralidade das ideologias, se tornaram também capitalistas. Mas o que me importa aqui falar, está além ou talvez mesmo aquém de conceitos de direita e esquerda, é sobre a classe, se é que possam ser "classificados", daqueles que são considerados como subalternos, os vadios, os não-cidadãos.

Dando um salto à frente (de 1789 para 1948 - quando emergiram as declarações supracitadas), penso que esses subalternos só foram incluídos dentro da visão de mundo eurocêntrica, quando algumas ONGs foram criadas um pouco antes da Declaração dos Direitos Humanos (diga-se de passagem, quando a Europa admitiu, que após duas guerras mundiais, seu plano iluminista de uma razão liberal falhou e gerou tantas mortes de inocentes). Digo isso justamente pelo fato de que até então, as condições de trabalho eram tão desumanas, que os outsiders eram, se é que não continuam sendo: invisíveis (cito o exemplo da Professora de Filosofia no IF Sertão que se fantasiou de faxineira). Por esse motivo, dentro da visibilidade de todos enquanto seres humanos, Eckel explica a importância das ONGs para essa solidificação solidária:

No que diz respeito às ONGs de direitos humanos altamente profissionais e
politicamente importantes, as mais importantes foram estabelecidas em décadas
anteriores à Declaração: a Liga Internacional pelos Direitos do Homem em 1941, a
Comissão Internacional de Juristas em 1952 e a Anistia Internacional em 1961. No
entanto, as ONGs passaram por profundas transformações institucionais, que atestaram
a crescente atratividade de seu projeto político e aumentaram significativamente seu
impacto na política internacional. O desenvolvimento da Anistia Internacional é um
exemplo poderoso (ECKEL, 2014, p. 228)

Nesse sentido, por volta da década de 70, os direitos humanos foram fundamentais para a descolonização dos países que sofreram com o imperialismo europeu, assim, vários países da África alcançaram a independência e as ONGs fizeram parte desse processo auxiliando tanto na consequência das guerras, como do pós-guerra por meio de ajudas humanitárias. 
Dentro desse contexto, entretanto, não deixo de ver criticamente essas ações e coloco aqui primeiramente a visão de pensadores africanos sobre a descolonização dos direitos humanos, Paulina Chiziane, escritora moçambicana, faz uma crítica ao imaginário direitos humanos por meios das ONGs. Em entrevista dada a Revista Bastião em 2014.

Eu já trabalhei muito com movimentos da sociedade civil. Uma sociedade civil, para ser
forte, tem de ser autônoma, financeira e politicamente, mas o que acontece com a maior
parte das organizações não governamentais (ONGs) em Moçambique não é isso. As
nossas ONGs dependem do financiamento estrangeiro, portanto, qualquer
posicionamento de um indivíduo dependente vai sempre tender para agradar àquele que
paga. [...] O que temos são grupos de pessoas que são financiadas por organizações
estrangeiras. Que, de certa maneira, fazem diferença, porque conseguem trazer uma nova
visão e conseguem dinamizar um pouco aquilo que é o país. [...] É como se as ONGs
pudessem suprimir o governo. Ora, isso não pode acontecer, não pode. Então são várias
questões que se podem levantar na volta desse assunto. A minha apreciação é que, de
fato, o trabalho das ONGS é bom ${ }^{1}$

Paulina Chiziane toca em um ponto crucial sentido de que Ongs não precisam ser órgãos internacionais, contudo Ongs que prestam ajuda internacional fazem importantes trabalhos no desenvolvimento social em países subdesenvolvidos. A escritora Paulina Chiziane faz uma crítica, mas por trás dessa crítica há o clamor de que o Estado deveria fazer o papel das ONGs. A pergunta que fica, o que falta aos Estados para que estabeleçam formas de humanismo efetivamente realizáveis, e que as ONGs não ajam para agradar aos organismos internacionais e tampouco o Estado, mas sim agradar o povo. Muitas outras iniciativas podem ser citadas nessa via, ONGs que auxiliam na manutenção de usuários de bicicleta como uma questão de políticas públicas voltadas ao transporte, ONGs que auxiliam na ocupação de espaços público por uma questão cultural. A pluralidade das ONGs é tão grande que eu poderia passar toda a minha comunicação citando exemplos significativos de trabalhos que interconectam lideranças de bairros e comunidades, sindicatos e cooperativas e etc. Um exemplo de uma ação que não pode deixar de ser mencionado sobre uma efetiva aliança de ONGs com o Estado foi o projeto de 1 milhão de Cisternas no Sertão, aliada as tecnologias 'populares' das calhas como aproveitamento das águas das poucas chuvas dessa região. A assistência técnica das ONGs que se dividem em milhões de ações descentralizadas me parece ser justamente a possibilidade de organização da sociedade civil de se mobilizar por sua própria autossuficiência.

Esclarecido esse meu ponto de vista, passo agora a sintetizar agora o argumento do filósofo Achille Mbembe, também africano e defensor da ideia da descolonização de diversos conceitos. Ele demonstra que a noção de cidadania iluminista foi trocada pela ideia do consumidor, contudo, essa virada não quer dizer uma valorização, mas sim o próprio fim do humanismo. Desse modo, 
A noção humanística e iluminista do sujeito racional capaz de deliberação e escolha será substituída pela do consumidor conscientemente deliberante e eleitor. Já em construção, um novo tipo de vontade humana triunfará. Este não será o indivíduo liberal que, não faz muito tempo, acreditamos que poderia ser o tema da democracia. O novo ser humano será constituído através e dentro das tecnologias digitais e dos meios computacionais. ${ }^{2}$

A partir dessas duas argumentações, em que a própria técnica começa a emergir e o antihumanismo andando de mãos dadas com o desprezo pela democracia nos vendendo a ilusão de que o consumismo é a cidadania chegamos então à descolonização do imaginário, nisso, nos próximos tempos então como devemos agir ou reagir? As certezas da religião, da hierarquia, tradição são reações contra o medo heteronormativo da perda de força dos valores patriarcais e messiânicos.

Voltamos então agora, após as claras inserções desses dois pensadores africanos que se estabelecem na história da filosofia de seus países, fazendo filosofia como algo que vai além do desafio colonialista de que "para fazer filosofia africana/americana é preciso pensar sem nenhuma referência europeia", sabemos que isso está ultrapassado na temática da descolonização, que a descolonização dos direitos humanos necessita uma análise pluriversa do imaginário intelectual para produção de novos sentidos da própria noção de direito.

Lembrando que o surgimento do direito se dá entre a contraposição da retórica do jusnaturalismo no qual a lei natural do mais forte prevalece enquanto convenção, e o juspositivismo pelo qual a adaptação do direito natural em forma de leis que levam a jurisprudências universalistas. O problema é que esse imaginário até então tem sido quando a retórica se torna fakenews, e o juspositivismo regride ao ponto de voltar ao jusnaturalismo da lei do mais forte em que o cotidiano vai sendo sutilmente militarizado. A tecnocracia das instituições de poder alimentaram juridicamente epistemicídios midiológicos (referência que faço à relação entre as operações mão lavadas na Itália e Lava Jato no Brasil, onde a venda de furos e reportagens fez com que a mídia ao final se vendesse ao um (des)governo que leva a sua própria censura). Cornelius Castoriadis, referência nos estudos do imaginário, vê então a necessidade então de descolonizar o imaginário como essência do sentido desse movimento, por conta da carga colonizadora retida no imaginário institucional latino-americano. Segundo Latouche:

Para Castoriadis, autor de A instituição imaginária da sociedade, a realidade social é a implementação de "significações imaginárias", ou seja, representações que mobilizam sentimentos. Se o crescimento e o desenvolvimento são crenças e, portanto, significações imaginárias, como "progresso", e todas as categorias fundacionais da economia, sair delas paira aboli-las e transcendê-las (a famosa aufhebung hegeliana) significa que o imaginário deve ser mudado. A realização de uma sociedade do decrescimento implica, portanto, em parte, descolonizar nosso imaginário, realmente mudar o mundo antes que a mudança do mundo nos condene (LATOUCHE, 2005, p. 119)

\footnotetext{
${ }^{2}$ http://www.ihu.unisinos.br/78-noticias/564255-achille-mbembe-a-era-do-humanismo-esta-terminando
} 
O que nos parece interessante na argumentação de Latouche é que ele de certa forma responde e corresponde as duas primeiras reflexões expostas até então. Sobre as Ongs, em primeiro lugar Latouche relembra uma renomeação agora como Organizações de Solidariedade Internacionais (OSI) e as coloca como problemática do 'Dom' justamente para desconstruir a falsa ideia de doar para dominar. Já sobre o direito, ele retoma o conceito de 'dom', emprestado do antropólogo de Marcel Mauss, ou também conhecido pela tradução Ensaio sobre a dádiva, que inspira essa nova nomenclatura se tratou de um estudo pós-colonial em que investiga as relações de dar, receber e retribuir em sociedades tribais e como tal interação no direito romano e em outras sociedades. Isso nos parece ter uma ligação direta com uma genealogia dos direitos humanos...

Contudo, do lado oposto do universalismo, temos que o regionalismo dos Direitos Humanos é um problema que tem a autossuficiência como questão fundamental. Para isso, Latouche propõe estabelecer que é o princípio de solidariedade aplicada que dá sentido a relação entre teoria e prática do que ele chama dos 8 "R"s:

Podemos, inspirados na Carta "Consumo e estilos de vida" proposto na ONG Fórum
Rio, sintetizar tudo isso em um programa de oito" R ": Reavaliar, reconceptualizando,
reestruturar, retransformar, redistribuir, Reduzir, Reutilizar. Esses objetivos
interdependentes colocam em movimento um círculo virtuoso de declínio sereno,
amigável e sustentável. Reavaliar significa rever os valores em que acreditamos e
organizamos nossas vidas e mudar aqueles que precisam ser mudados. aparato de
produção e relações sociais de acordo com a mudança de valores. Redistribuição significa
a distribuição de riqueza e acesso ao patrimônio natural. Reduzir significa reduzir o
impacto sobre a biosfera de nossos modos de produção e reutilizar em vez de descartar
aparelhos e mercadorias e, claro, reciclar o lixo incompressível da nossa atividade. Se um
desafio radical aos valores da modernidade é necessário, isso não implica necessariamente
a rejeição de qualquer ciência ou a rejeição de qualquer técnica. (LATOUCHE, 2005, p.
18)

Assim, estamos justamente nesse momento histórico de repensarmos e nos autoavaliarmos criticamente em todas as posições e instituições. Porque o contrário disso, segundo Latouche, é a megamáquina, que além de não pensar, faz com que a sociedade se deixa levar roboticamente, após a invenção da roda talvez o problema mais fundamental a que chegamos é como lidar com o imaginário da máquina, quem não quer ter um carro, eletrodomésticos e tantos outros utilitários que facilitam a nossa vida e que em certa medida tiram de nós a nossa criatividade de fazer?

Nessas organizações de massa, combinando força militar, eficiência econômica, autoridade religiosa, desempenho técnico e poder político, o homem se torna a engrenagem de uma complexa mecânica que atinge quase o poder absoluto: uma megamáquina. (LATOUCHE, 2005, p. 39)

Relegamos o poder absoluto à uma máquina ou ao homem máquina, híbrido, artificial, inorgânico? Sobre o símbolo imaginário da mão invisível, ou de muitas outras metáforas e imagens 
da alienação humana, as técnicas biopolíticas se articulam em uma fusão que não utiliza mais máquinas para seus fins próprios, a máquina é o meio e o fim, porque precisamos sustentá-la com números que mantenham nosso status quo que nos livrem do apocalipse. A técnica progride transnacionalmente vendendo suas inovações e promovendo a tendência própria do ser humano de se tornar um vigilante do outro, numa eterna coação mútua.

Como pensar que então num caminho em que o pessimismo necropolítico Mbembe não destrua toda essa construção de direitos humanos? Quando absorvo a crítica de que os direitos humanos são racistas na medida em que num iluminismo o homem é uma mercadoria, portanto, como podemos redimensionar o dualismo em que a subjetividade humana é objetivada num eterno retorno das micropolíticas que sustentam nossas relações humanas (como a própria tendência dos relacionamentos por meio de redes sociais, tinder, etc.)?

De fato, ainda há resquícios do imaginário da libertação versus a escravidão. Evidentemente, a escravidão ainda não acabou, ela segue no imaginário das relações entre patrões (capital) e empregados (mão de obra). Mas há uma superação dessa dialética na medida em que o pós-modernismo, com a dissolução do sujeito, nos dá uma brecha para a descolonização. Mas não uma descolonização como purificação dos conceitos e objetos, ora, a ideia de posse das ideias está ultrapassada, no campo semântico da intelectualidade tudo já foi pensado por outros, e o que é possível fazer é direcionar a história do pensamento nessa relação de uma renovação do imaginário contra o fim do humanismo.

\section{Considerações finais}

Entender que precisamos revolucionar a nossa visão enquanto indivíduos, percebendo que estamos agora numa guerra imaginária e que a sustentação dos direitos humanos como concepção resultante de um indivíduo racional e autosuficiente não dá conta da transmodernidade que acaba por legitimar somente a parte o ideário moderno-burguês. Me parece que no contexto político atual, a burguesia e a classe média ressaltam uma total falta de criatividade em termos de valores políticos, tanto que partidos, seitas, sindicatos e ONGs são atacados e coagidos por uma megamáquina tecnocrática. A tecnocracia não tem ressentimento nem a decepção que o imaginário atual reverbera, mas também não tem a esperança e a luta tem que ser por uma desobediência epistêmica. "Aonde a onda anda" como diria nosso célebre Manuel Bandeira, é saber descolonizar e recriar as ondas imaginárias que dão sentido a nossa concepção de ser humano.

A questão se trata de dar sentido ao pós-humanismo a partir da memórias e as feridas coloniais. Quais são as feridas dos direitos humanos? Um discurso dominante histórico e parcial, 
no qual uma humanidade apta a gozar dos mesmos direitos seria também uma negação homogeneizante da diversidade de outros direitos culturais. O significado de humano e humanidades, em seus valores simbólicos, tende a excluir o imaginário da hibridez e da multiplicidade. Para Castoriadis e Latouche tal ímpeto não é simplesmente de uma metafísica ocidental, mas sim do imaginário da expansão ilimitada da razão. Por isso, a razão, desde o seu princípio da não contradição, nos levou à bomba atômica e agora, só uma desconstrução do pensar para um sentipensar, pode nos levar novamente à uma alteridade solidária do dom.

Em Democracia e relativismo, uma série de entrevistas de Castoriadis com vários intelectuais, uma das conclusões que se chega é que apesar da democracia poder estar morrendo, como sempre esteve aliás, mas ela ainda irá renascer. Cabe a nós promover esse renascimento a partir dos erros encontrados e renovar o imaginário de uma nova democracia.

\footnotetext{
Uma nova cultura surgirá e verá o renascimento da política, novas relações com o meio ambiente, uma nova ética. Este será o resultado de um trabalho histórico, e não o fruto de um voluntarismo tecnocrático, seja populista, nacionalista, teocrático ou que definese - como autodefinição - certo ou errado. (LATOUCHE, 2005, p. 151).
}

Superando esses dualismos, por fim, entendo que o imaginário dos direitos humanos por meio das ONGs é uma proposta viável de atuação social, da palavra agora proibida de "ativismo" (curiosamente, fora o significado de militância em meios revolucionários, estudantis e sindicais, ativismo significa filosoficamente a prática efetiva da transformação em detrimento da especulação) que também deverá ser descolonizada por um novo conceito que deveremos criar enquanto focos de resistência e de ações inteligentes. Nesse sentido, é hora das mídias passarem a se voltar para as formas de ativismo, para as ONGs, e para as ações locais, pois o que veremos é o enfraquecimento dos grandes meios de comunicação na era da pós-verdade.

Seguiremos então nesse exercício de descolonização em busca de novos horizontes possíveis, frente as utopias que já realizamos, Canudos, Pau e Colher, qual será a nossa próxima heterotopia possível no sertão filosófico? Novas formações técnicas e acadêmicas, um evento, uma nova biblioteca virtual, ou simplesmente uma união entre professores e alunos numa horizontalidade de saberes que nos façam conhecer e reconhecermos também a nós mesmos enquanto novos pensadores, como estes que necessitam absorver novas técnicas micropolíticas que derrotem a megamáquina. Por fim, com a escola sem partido e toda a abolição das ideologias de gênero, vamos também encontrar essa nova posicionalidade da desconstrução decolonial do imaginário: a filosofia dos direitos, que não podem ser desumanos, sobreviverá junto com toda a carga epistêmica rejeitada pelo protofascismo. Isso nos deixa impassíveis diante dos ataques injustificáveis que ONGs vem sofrendo mesmo no Brasil, o aparato estatal não dá conta do recado e quer ainda culpar aqueles que fazem o trabalho complementar de atrapalhar a guinada do neoliberalismo autoritário. 
Referências Bibliográficas

CASTORIADIS, C. Démocratie et relativisme: dévat avec le MAUSS. Paris: Mille et Une Nuits. 2010.

LATOUCHE, S. Décoloniser l'imaginaire La pensée créative contre l'économie de l'absurde. Lyon: Parangon, 2005.

ECKEL, The rebirth of politics from the spirit of morality: explaining the human rights revolution of the 1970s, in Eckel, Jan, Moyn, Samuel (eds.), The Breakthrough: Human Rights in the 1970s. Philadelphia: University of Pennsylvania Press 2014. pp. 226-261 